\title{
Offshoring to a Developing Nation with a Dual Labor Market
}

\author{
Subhayu Bandyopadhyay, Arnab Basu, Nancy Chau, and Devashish Mitra
}

\begin{abstract}
We present a model of offshoring of tasks to a developing nation characterized by a minimum-wage formal sector and a flexible-wage informal sector. Some offshored tasks are outsourced by the formal sector to the lower-wage informal sector. Productivity improvements in performing offshored tasks in the developing nation increase offshoring, but not necessarily formal-to-informal sector outsourcing, which can cause the developed nation's wage to fall. Productivity improvements in the developing nation's informal sector expand both offshoring and outsourcing, causing the developed nation's wage to rise. When the minimum wage is reduced in the developing nation, the developed nation's wage falls when most of the efficiency gains accrue to the informal sector. (JEL F1)
\end{abstract}

Federal Reserve Bank of St. Louis Review, Third Quarter 2020, 102(3), pp. 237-53.

https://doi.org/10.20955/r.102.237-53

\section{INTRODUCTION}

This article analyzes developed-to-developing nation offshoring in the presence of a dual labor-market structure in the developing nation. While the developed nation's labor market is assumed to feature flexible wages and full employment, the developing nation is characterized by a dual labor market where a formal and an informal sector coexist. While the formal sector is subject to a minimum-wage regulation, the informal sector is assumed to be able to circumvent that law or the law does not apply to it and pay a lower market-clearing wage. It is also possible that the formal sector circumvents the law by outsourcing to the informal sector or hiring informal or casual workers to perform certain tasks. Consideration of labormarket duality leads to some important departures from the existing literature on trade in tasks, which was pioneered by Grossman and Rossi-Hansberg (2008, GRH hereafter) among others.

As described in Bhagwati and Panagariya (2013), India has over 200 labor regulations that apply to firms in the formal sector. These regulations make labor costs higher than what they otherwise would be and adversely affect the flexibility of firms in responding to shocks.

Subhayu Bandyopadhyay is a research officer and economist at the Federal Reserve Bank of St. Louis. Arnab Basu and Nancy Chau are professors at the Charles H. Dyson School of Applied Economics and Management at Cornell University. Devashish Mitra is a professor at The Maxwell School of Citizenship and Public Affairs at Syracuse University. The authors thank two anonymous referees for their very helpful comments.

(c) 2020, Federal Reserve Bank of St. Louis. The views expressed in this article are those of the author(s) and do not necessarily reflect the views of the Federal Reserve System, the Board of Governors, or the regional Federal Reserve Banks. Articles may be reprinted, reproduced, published, distributed, displayed, and transmitted in their entirety if copyright notice, author name(s), and full citation are included. Abstracts, synopses, and other derivative works may be made only with prior written permission of the Federal Reserve Bank of St. Louis. 


\section{Bandyopadhyay, Basu, Chau, Mitra}

In practice, firms find ways of getting around these labor regulations by incurring some costs. For example, Ramaswamy (2003) documents that formal sector manufacturing firms in India are able to circumvent labor regulations by hiring temporary (casual) or contract workers to whom those regulations do not apply. Hasan and Jandoc (2013) show that even in large Indian manufacturing firms with employment over 200 workers, casual or contract workers constitute about 30 percent of total employment. Harris-White and Sinha (2007) provide anecdotal evidence supporting outsourcing of certain activities from formal sector to informal sector firms in India. Sundaram (2015) also provides evidence indicative of outsourcing of relatively labor-intensive activities from formal sector to informal sector firms in India. And, finally, Sundaram, Ahsan, and Mitra (2012, p. 79) provide evidence of "linkages between the formal and informal manufacturing sectors through outsourcing." In addition to the evidence for India, there is also evidence for Mexico showing that about 25 percent of employees of formal firms are informal workers; thus, formal firms are able to avoid many labor regulations (Samaniega de la Parra, 2016).

The paper by GRH is one of the first to model trade in tasks in the context of a developed nation offshoring tasks to a lower-wage nation. The paper's structure is similar to neoclassical competitive models of trade. Accordingly, as in the Heckscher-Ohlin type framework, a reduction in the cost of offshoring has a positive wage effect similar to a productivity increase. This leads to the somewhat counterintuitive result that technological improvements in offshoring that lead to more tasks being offshored can actually lead to a higher wage for labor in the developed nation. This is possible because technological improvements lead to cost savings and scale expansion, and these are reflected in a higher domestic wage at full employment. The paper by GRH focuses on the developed nation, and the nation that performs the offshored tasks is modeled simply as a nation with a fixed wage.

Bandyopadhyay et al. (2020) provide a model for the joint determination of wages in the developed (source) nation that offshores tasks and a developing (recipient) nation that completes the tasks. Within the context of this model, they derive several results that show that while a developed nation may gain from technological improvements in offshoring, the developing nation could lose if the labor-saving effect of technological improvements outweighs the scale-expansion effect. One major issue not considered by Bandyopadhyay et al. (2020) is the importance of the informal sector in developing nations. Indeed, while the formal sector can feasibly be monitored by the government, the informal sector is often out of reach of government regulations. This means that labor standards or minimum-wage laws are hard to enforce in the informal sector, which creates an incentive for firms to outsource some of their tasks to the informal sector. Keeping this duality between the formal and informal sectors in mind, we analyze how technological improvements may impact wages and employment in a simultaneous labor market equilibrium in three markets: the developed nation's labor market, the developing nation's formal sector labor market, and finally the developing nation's informal sector labor market.

We build a model where two nations, which are small in the output market, have a bilateral

offshoring relationship in the production of a manufacturing good. 1 As in GRH, competitive firms based in the developed nation produce this good by completing a range of tasks. Some 
of these tasks are relatively complex and require more labor to be completed in the developing nation, so they are completed in the developed nation, where it is cheaper, while the rest of the tasks are offshored. Among the offshored tasks, intermediate-complexity tasks are completed in the developing nation's minimum-wage formal sector, while the least-complex tasks are completed in its lower-wage informal sector where it is cheaper. ${ }^{2}$ This second layer of task allocation is commonly referred to as "domestic outsourcing," which allows formal sector firms to circumvent the minimum wage. $\frac{3}{}$

The focus of our general equilibrium model is simultaneous labor market clearing in the developed and the developing nations, where each nation has two sectors, a manufacturing sector and a numeraire agricultural (food) sector. ${ }^{4}$ In the developing nation, there is a dual labor market characterized by a rigid-wage formal manufacturing sector and a common flexible wage in the informal manufacturing sector and the agricultural sector. Flexible wages characterize the developed nation's labor market. The residual labor supplies of the manufacturing sectors are absorbed by the respective agricultural sectors of the two nations. We primarily analyze how the flexible wages in the two nations are affected by changes in offshoring technology and outsourcing technology. We also analyze how these factors and parametric changes affect other endogenous variables of interest, such as the levels of offshoring and outsourcing and the share of the informal sector in the developing nation's economy.

The comparative static analysis yields some results that depart from the existing literature. For example, while a rise in offshoring productivity raises offshoring, it may reduce the developed nation's wage. This can happen because the developing nation's informal sector wage may rise through offshoring demand effects and also because of the accompanying shift of marginal tasks from the low-wage informal sector to the higher-wage formal sector. As a result, the degree of informality, given by the ratio of informal-to-formal sector manufacturing employment, may fall. Some other results are counterintuitive at first glance. For example, although increased informal sector productivity in the developing nation will raise formalto-informal sector (formal-informal) outsourcing, it may reduce both the informal sector's wage and the degree of informality in the nation's manufacturing sector. Similarly, while a minimum-wage cut reduces informality, it may actually increase the informal wage.

Section 2 presents the model and the description of the equilibrium. Section 3 presents comparative static analyses. Section 4 concludes.

\section{THE MODEL AND EQUILIBRIUM}

\subsection{The Basic Structure}

Consider two nations, a developed nation $F$ and a developing nation $H$. There are two homogeneous goods, a numeraire manufactured good and food. We assume that the two nations are small in the output market, so the prices of both goods can be set at unity, without loss of generality. The output levels of the manufactured good and food in nation $F$ are denoted by $x^{*}$ and $y^{*}$, respectively. Nation $H$ also produces food, for which the output level is denoted by $y$, and workers in nation $H$ may also perform tasks offshored by nation $F$ 's manufacturing 


\section{Bandyopadhyay, Basu, Chau, Mitra}

sector. For simplicity, we assume that all of the manufacturing sector's activity in $H$ is completion of the tasks offshored by $F$.

Following GRH, we assume that production of a unit of $x^{*}$ requires a continuum of labor tasks $i \in[0,1]$ to be performed either in $H$ or in $F$. Labor is the only input used to perform the required tasks. While each task $i$ requires a unit of labor in $F$, the same task requires $\beta t(i)>1$ units of labor in $H$, where $\beta$ is a general technology parameter and $t(i)$ is the part of technology specific to task $i$ in nation $H$. Tasks that are more complex and require more labor to complete in the developing nation are indexed by higher values of $i$. Therefore, by construction $t^{\prime}(i)>0$.

Developing nations are often characterized by a dual labor-market environment, where a formal manufacturing sector coexists with (i) an informal manufacturing sector and (ii) the food (agricultural) sector. The formal manufacturing sector features large and well-organized firms bound by laws and regulations: They are required to pay corporate income taxes, get import licenses, have labor unions, etc. The informal manufacturing sector and the agricultural sector are usually characterized by small firms or farmers in rural settings, respectively, where labor laws and regulations do not apply or are not enforceable (because of prohibitive monitoring costs). Accordingly, we first assume that there is a minimum wage in the formal manufacturing sector and a flexible wage in the informal manufacturing sector, where the latter conducts the simplest of manufacturing tasks and is characterized by perfect labor mobility with the agricultural sector. Second, we assume that completion of tasks in the informal sector involves some additional costs. These costs may arise because of a lack of infrastructure that allows the simplest tasks to be transported to the informal sector or the inferior production technology that characterizes the informal sector. Furthermore, to the extent that the informal sector has more infrastructure constraints, such as unreliable electricity, worker productivity in the sector suffers. Since higher values of $i$ represent more-complex tasks, the labor required to outsource from the formal to the informal sector is assumed to be an increasing markup over the labor required to complete the task in the formal sector. This markup is $\tilde{\beta} \tau(i)$, where $\tilde{\beta}$ is a general informal sector technology parameter and $\tau^{\prime}(i)>0$ captures that the informal sector is less technologically advanced and thus has increasing difficulty in completing more-complex tasks. The labor required to complete task $i$ in the informal sector is then $\tilde{\beta} \tau(i) \beta t(i)$.

Denoting land and labor by $T$ and $L$, respectively, the constant-returns-to-scale (CRS) production function for food in nation $H$ is $y=G\left(L_{y}, T\right)$, where $L_{y}$ is labor used in $H$ 's agricultural sector. Similarly, $y^{*}=G^{*}\left(L_{y}^{*}, T^{*}\right)$ represents nation $F^{\prime}$ s production function for food. Since land is specific to food production and its endowment in each nation is fixed, the CRS production functions for food in the two nations are characterized, respectively, by diminishing returns to labor:

$$
\begin{aligned}
& y=G\left(L_{y}, T\right), G_{L_{y}}\left(L_{y}, T\right)>0, G_{L_{y} L_{y}}\left(L_{y}, T\right)<0 \text { and } \\
& y^{*}=G^{*}\left(L_{y}^{*}, T^{*}\right), G_{L_{y}^{*}}^{*}\left(L_{y}^{*}, T^{*}\right)>0, G_{L_{y}^{*} L_{y}^{*}}^{*}\left(L_{y}^{*}, T^{*}\right)<0 .
\end{aligned}
$$




\subsection{The Labor Supply in the Manufacturing Sector}

Let us denote the developed nation's wage by $w^{*}$ and the developing nation's wage in the agricultural sector as $w$. Recalling that output prices are fixed at unity, competitive profitmaximization conditions in the agricultural sectors in nations $H$ and $F$ are $w=G_{L_{y}}\left(L_{y}, T\right)$ and $w^{*}=G_{L_{y}^{*}}^{*}\left(L_{y}^{*}, T^{*}\right)$, respectively. Inverting these functions and suppressing $T$ and $T^{*}$ from the functional forms, we obtain the respective labor demand functions in $H$ and $F$ as

$$
\begin{aligned}
& L_{y}^{d}=L_{y}^{d}(w), L_{y}^{d^{\prime}}(w)<0 \text { and } \\
& L_{y}^{* d}=L_{y}^{*}\left(w^{*}\right), L_{y}^{* d^{\prime}}\left(w^{*}\right)<0 .
\end{aligned}
$$

Given the respective labor endowments $\bar{L}$ and $\bar{L}^{*}$ of nations $H$ and $F$, the labor supply functions for the manufacturing sectors of nations $H$ and $F$ are respectively given by $\underline{5}$

$$
\begin{gathered}
L(w)=\bar{L}-L_{y}^{d}(w), L^{\prime}(w)>0 \text { and } \\
L^{*}\left(w^{*}\right)=\bar{L}^{*}-L_{y}^{*}\left(w^{*}\right), L^{* \prime}\left(w^{*}\right)>0 .
\end{gathered}
$$

\subsection{Offshoring to the Developing Nation: Formal-Informal Task Allocation}

We assume that technology in the agricultural sectors and endowments in the two nations are such that the developed nation's wage $w^{*}$ exceeds the developing nation's minimum wage $\bar{w}$ in its formal manufacturing sector. ${ }^{6}$ Labor mobility between $H$ 's informal sector and agricultural sector equalizes the wage between these sectors at $w$. Although $w^{*}$ and $w$ are endogenous, labor-allocation decisions are best explained for a given vector of wage rates $\left(w^{*}, \bar{w}, w\right)$. Any task $i$ can be completed by a unit of labor in $F$ at a cost of $w^{*}$. This same task can be completed in nation $H$ 's formal sector at a lower wage rate $\bar{w}$, albeit with a greater labor requirement $\beta t(i)>1$. The cost of completing this task in $H$ 's formal sector is $\bar{w} \beta t(i)$. As $i$ goes to zero, we have tasks that are less complex and the labor cost of completing these tasks in the developing nation are small enough such that $\bar{w} \beta t(i)<w^{*}$ and hence the developed nation offshores these tasks. On the other hand, as $i$ goes to 1 , we assume that the tasks require sufficiently more labor to be completed in the developing nation such that $\bar{w} \beta t(i)>w^{*}$, so the tasks are completed in the developed nation. Given continuity and monotonicity of the underlying functions, the marginal offshored task is denoted by $I$, where

$$
\bar{w} \beta t(I)=w^{*} \Leftrightarrow t(I)=\rho_{I} \Rightarrow I=I\left(\rho_{I}\right), I^{\prime}\left(\rho_{I}\right)=\frac{1}{t^{\prime}(I)}>0,
$$

where $\rho_{I}=w^{*} /(\beta \bar{w})$ is the effective relative factor price of completing a task in the developed nation. Thus, tasks in the range $i \in[0, I]$ are offshored, while the remaining tasks $i \in[I, 1]$ are completed in the developed nation. Next, notice that for the minimum wage to be binding, the informal sector of the developing nation must have a lower wage $w$. The least-complex offshored tasks (i.e., as $i$ goes to zero) can be performed in the informal sector at a lower cost $w \tilde{\beta} \tau(i) \beta t(i)$ than in the formal sector, where the cost is $\bar{w} \beta t(i)$. This is true for all tasks where 


\section{Bandyopadhyay, Basu, Chau, Mitra}

$w \tilde{\beta} \tau(i)<\bar{w}$. On the other hand, the most-complex offshored task (i.e., $i=I$ ) is such that the high labor requirement dominates the wage advantage of the informal sector, such that $w \tilde{\beta} \tau(I)>\bar{w}$. Thus, task $I$ is completed in the developing nation's formal sector. The marginal task outsourced from the formal to the informal sector is $J$, where

$$
w \tilde{\beta} \tau(J)=\bar{w} \Leftrightarrow \tau(J)=\rho_{J} \Rightarrow J=J\left(\rho_{J}\right), J^{\prime}\left(\rho_{J}\right)=\frac{1}{\tau^{\prime}(J)}>0,
$$

where $\rho_{J}=\bar{w} /(\tilde{\beta} w)$ is the effective relative factor price of completing an offshored task in the developing nation's formal sector (relative to the informal sector). Given the assumed continuity and monotonicity of the $\tau(i)$ function, (8) implies that out of the offshored tasks, $i \in[0, J]$ are completed in the informal sector and the remainder $i \in[J, I]$ are completed in the formal sector.

\subsection{Equilibrium}

Given that the manufacturing good is produced through a CRS production technology where each task requires a unit of labor, $(1-I)$ tasks that remain in the developed nation require $x^{*}(1-I)$ units of labor when output is $x^{*}$. Thus, in the presence of offshoring, the labor demand in the manufacturing sector in the developed nation is $x^{*}(1-I)$. Labor demand in the agricultural sector $y^{*}$ of the developed nation is $L_{y}^{* d}\left(w^{*}\right)$. Thus, using equation (6), the developed nation's labor market-clearing condition where the aggregate demand for labor from the two sectors equals the labor endowment $\bar{L}^{*}$ is

$$
x^{*}(1-I)+L_{y}^{*}\left(w^{*}\right)=\vec{L}^{*} \Leftrightarrow x^{*}(1-I)=L^{*}\left(w^{*}\right) .
$$

Let us now consider labor required to complete the offshored tasks $i \in[0, I]$. Notice that an offshored task $i$ performed in the developing nation's formal sector requires $\beta t(i)$ labor units. Furthermore, only tasks $i \in[J, I]$ are completed in the formal sector. Since the labor required to complete these tasks vary in the developing nation, the total labor used for completion of these tasks per unit of output is $\beta \int_{J}^{I} t(i) d i$ in that nation. Therefore, to produce $x^{*}$ units of output, the labor required in the developing nation's formal sector is $x^{*} \beta \int_{J}^{I} t(i) d i$. Similarly, $\beta \tilde{\beta} t(i) \tau(i)$ is the labor requirement to complete a task $i$ in the informal sector, where tasks in the range $i \in[0, J]$ are completed. Thus, production of $x^{*}$ units of output leads to an informal sector labor demand of $x^{*} \beta \tilde{\beta} \int_{0}^{J} t(i) \tau(i) d i$. Labor demand in the developing nation comes from three sources: the formal manufacturing sector, the informal manufacturing sector, and the agricultural sector. The labor demand in the agricultural sector is $L_{y}^{d}(w)$. The developing nation's labor market clears when the aggregate labor demand of these three sectors equals the developing nation's labor endowment such that using equation (5) we have

$$
x^{*} \beta \int_{J}^{I} t(i) d i+x^{*} \beta \tilde{\beta} \int_{0}^{J} t(i) \tau(i) d i+L_{y}^{d}(w)=\bar{L} \Leftrightarrow x^{*} \beta\left[\tilde{\beta} \int_{0}^{J} t(i) \tau(i) d i+\int_{J}^{I} t(i) d i\right]=L(w) .
$$


The flexible-wage rates of the two nations $\left(w, w^{*}\right)$ adjust to clear their respective labor markets simultaneously.

It is convenient to analyze equations (9) and (10) in the form of relative demand and supply between the two nations. If we take the ratio of the left-hand sides of the second equalities in equations (9) and (10), we get the relative demand for labor in the manufacturing sectors of the two nations. Similarly, the ratio of the right-hand sides of the same equations yields the relative supply of labor in the manufacturing sectors of the two nations. The relative demandsupply equality is ${ }^{7}$

$$
\beta[\tilde{\beta} \mu(J, I)+\gamma(J, I)]=\frac{L(w)}{L^{*}\left(w^{*}\right)},
$$

where $\mu(J, I)=\left(\int_{0}^{J} t(i) \tau(i) d i\right) /(1-I)$ and $\gamma(J, I)=\left(\int_{J}^{I} t(i) d i\right) /(1-I)$. Notice that $\mu(\cdot)$ can be written as $\mu(J, I)=\left[\left(\int_{0}^{J} t(i) \tau(i) d i\right) x^{*}\right] /\left[(1-I) x^{*}\right]$, which is the parameter-adjusted labor demand of the developing nation's informal sector (i.e., informal sector's labor demand divided by $\beta \tilde{\beta}$ ) relative to labor demand in the developed nation's manufacturing sector. Similarly, $\gamma(\cdot)$ is the parameter-adjusted labor demand in the developing nation's formal sector (i.e., formal sector's labor demand divided by $\beta$ ) relative to the labor demand in the developed nation's manufacturing sector. When offshoring is high, $I$ is larger, and given $J$, relative demand $\mu(\cdot)$ has to be higher because the unit labor demand in the developed nation's manufacturing sector (i.e., $1-I$ ) is lower. Similarly, given $J, \gamma(\cdot)$ is increasing in $I$ because of two effects: (i) the aforementioned effect of a reduction in unit labor demand in the developed nation's manufacturing sector and (ii) the expansion of the upper limit of the range $[J, I]$ of tasks performed in the developing nation's formal sector. Similarly, one can explain the effects of changes in $J$ given $I$. In reality, both $(I, J)$ change in response to changes in relative prices $\left(\rho_{I}, \rho_{J}\right)$, as described in equations (7) and (8).

The cost of producing a unit of $x^{*}$ is the sum of the costs of completing all tasks necessary to produce that unit. The cost of completing $(1-I)$ tasks in the developed nation is $w^{*}(1-I)$, while the cost of completing the offshored tasks in the developing nation's formal and informal sectors are $\bar{w} \beta \int_{J}^{I} t(i) d i$ and $w \beta \tilde{\beta} \int_{0}^{J} t(i) \tau(i) d i$, respectively. Noting that the price of good $x^{*}$ is unity, the zero profit condition for the good is

$$
w^{*}(1-I)+\beta\left[w \tilde{\beta} \int_{0}^{J} t(i) \tau(i) d i+\bar{w} \int_{J}^{I} t(i) d i\right]=1 .
$$

Equations (11) and (12) jointly determine the international equilibrium $\left(w, w^{*}\right)$ at a given minimum wage $\bar{w}$ and for given technology parameters $\beta$ and $\tilde{\beta}$. 


\section{COMPARATIVE STATICS}

The offshoring equilibrium is affected by various parameters underlying the model described in the previous section and also by the minimum wage $\bar{w}$. This section explores how the equilibrium is affected by (i) a change in offshoring technology parameterized by $\beta$, (ii) a change in $\tilde{\beta}$ reflecting changes in outsourcing technology related to formal-informal outsourcing within the developing nation, and (iii) a change in the minimum wage in the developing nation's manufacturing sector. In particular, we focus on how changes in these parameters or policy variables affect offshoring (from the developed nation to the developing nation) and outsourcing (from the developing nation's formal to informal sector), the wages in the two nations, and the share of the informal sector in the total manufacturing employment of the developing nation. We first derive some equations that apply to all of the aforementioned parameter and policy changes. After that, we analyze offshoring technology and outsourcing technology changes in Sections 3.1 and 3.2, respectively, and finally the effects of changes in the minimum wage in Section 3.3. Propositions 1, 2, and 3 correspond to Sections 3.1, 3.2, and 3.3 and summarize the findings of each of these subsections.

Let us define the share of the informal sector employment in total manufacturing sector employment in the developing nation as $\delta=\frac{\left(\tilde{\beta} \int_{0}^{J} t(i) \tau(i) d i\right) x^{*}}{\left(\tilde{\beta} \int_{0}^{J} t(i) \tau(i) d i+\int_{J}^{I} t(i) d i\right) x^{*}}$. Using the definitions of $\mu$ and $\gamma$ above, this reduces to $\delta=\frac{\tilde{\beta} \mu}{\tilde{\beta} \mu+\gamma}$. Next, consider the elasticity of the relative demand for labor (see equation (11)) with respect to change in the relative factor price $\rho_{I}$, given $\left(\beta, \tilde{\beta}, \rho_{J}\right)$. This elasticity is $\xi^{I}=\frac{d \ln \beta(\tilde{\beta} \mu+\gamma)}{d \ln \rho_{I}}=\delta \frac{\partial \ln \mu}{\partial \ln \rho_{I}}+(1-\delta) \frac{\partial \ln \gamma}{\partial \ln \rho_{I}}$ and strictly positive for the following reasons: Given $\rho_{J}$, $J$ is fixed and the rise in $\rho_{I}$ raises $I$. On inspection of the respective expressions for $\mu(\cdot)$ and $\gamma(\cdot)$ provided below equation (11), it is clear that both these functions are strictly increasing in $I$. Thus, a rise in $\rho_{I}$ must raise $\mu(\cdot)$ and $\gamma(\cdot)$, which means that $\xi^{I}=\delta \frac{\partial \ln \mu}{\partial \ln \rho_{I}}+(1-\delta) \frac{\partial \ln \gamma}{\partial \ln \rho_{I}}>0$. This elasticity is critical to understanding how the margin for offshoring shifts in response to parametric changes. For example, when $\beta$ falls, the first-round effect is an increase in the relative price $\rho_{I}=w^{*} /(\beta \bar{w})$, which reflects the fact that at a lower $\beta$, an offshored task can be performed at a lower wage cost in the developing nation's formal sector. The marginal offshored task increases until the difficulty of transporting the new marginal task offsets the cost savings from technological improvements. As more tasks are offshored, the relative labor demand of the developing nation's formal sector rises, with this effect measured by the term $\frac{\partial \ln \gamma}{\partial \ln \rho_{I}}$. Similarly, the relative labor demand of the developing nation's 
informal sector rises as the unit labor demand of the developed nation's manufacturing sector falls, with this effect measured by the term $\frac{\partial \ln \mu}{\partial \ln \rho_{I}}$.

Aggregating these effects by weighting them by the shares $\delta$ and $1-\delta$ of the developing nation's informal and formal sectors, respectively, we get the effect on relative labor demand from a rise in the relative factor price $\rho_{I}$. This effect is captured by $\xi^{I}$ above. Similarly, given $\rho_{I}$, $I$ is fixed by equation (7) and we can explore the effect of a change in $\rho_{J}$ on relative labor demand through changes in the outsourcing range $[0, J]$. The effects of changes in $\rho_{J}$ on relative demand can be expressed by another elasticity represented as a weighted average:

$\xi^{J}=\frac{d \ln \beta(\tilde{\beta} \mu+\gamma)}{d \ln \rho_{J}}=\delta \frac{\partial \ln \mu}{\partial \ln \rho_{J}}+(1-\delta) \frac{\partial \ln \gamma}{\partial \ln \rho_{J}}$.

This elasticity must also be positive because given $\rho_{I}$, $I$ is fixed and the rise in $\rho_{J}$ raises $J$, which

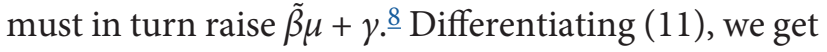

$$
\left(\eta^{*}+\xi^{I}\right) \hat{w}^{*}-\left(\eta+\xi^{J}\right) \hat{w}=\left(\xi^{I}-1\right) \hat{\beta}+\left(\xi^{J}-\delta\right) \hat{\tilde{\beta}}+\left(\xi^{I}-\xi^{J}\right) \hat{\bar{w}} .
$$

Equation (13) yields an upward-sloping locus in $\left(w, w^{*}\right)$ space because a higher $w^{*}$ increases offshoring, raising labor demand in nation $H$ so that labor markets of the two nations clear after a suitable increase in the wage rate $w$. Differentiating (12) we get

$$
\theta^{*} \hat{w}^{*}+\left(1-\theta-\theta^{*}\right) \hat{w}=-\left(1-\theta^{*}\right) \hat{\beta}-\left(1-\theta-\theta^{*}\right) \hat{\tilde{\beta}}-\theta \hat{\bar{w}}
$$

where $\theta^{*}$ is $F^{\prime}$ s cost share in the production of $x^{*}, \theta$ is $H^{\prime}$ 's corresponding cost share of $i t s$ formal sector, and the remainder $\left(1-\theta-\theta^{*}\right)$ is $H^{\prime}$ 's cost share of its informal sector. This relationship yields a familiar negative relationship corresponding to the zero-profit condition in the factor price space $\left(w, w^{*}\right)$. Given the output price, a higher wage for labor in nation $F$ can be consistent with zero profit only if the wage for nation $H$ 's labor is lower.

\subsection{Technological Improvements in Offshoring (Fall in $\beta$ )}

Using equations (13) and (14,) we consider the effects of a change in $\beta$ (i.e., inverse of labor productivity of offshoring) on $w$ and $w^{*}$ for a given vector $(\tilde{\beta}, \bar{w})$ :

$$
\begin{aligned}
& \frac{\hat{w}}{\hat{\beta}}=\frac{-\theta^{*}\left(\xi^{I}-1\right)-\left(1-\theta^{*}\right)\left(\eta^{*}+\xi^{I}\right)}{\theta^{*}\left(\eta+\xi^{J}\right)+\left(1-\theta^{*}-\theta\right)\left(\eta^{*}+\xi^{I}\right)} \text { and } \\
& \frac{\hat{w}^{*}}{\hat{\beta}}=\frac{\left(1-\theta^{*}-\theta\right)\left(\xi^{I}-1\right)-\left(1-\theta^{*}\right)\left(\eta+\xi^{J}\right)}{\theta^{*}\left(\eta+\xi^{J}\right)+\left(1-\theta^{*}-\theta\right)\left(\eta^{*}+\xi^{I}\right)} .
\end{aligned}
$$

Proposition $1 . \stackrel{9}{ }$ A reduction in $\beta$ leads to

(i) an increase in the range of offshoring $[0, I]$,

(ii) an increase in $w$ and a decrease in the range offormal-informal outsourcing $[0, J]$ if and only if $\xi^{I}>\theta^{*}-\eta^{*}\left(1-\theta^{*}\right)$, 
(iii) an increase in $w^{*}$ if and only if $\xi^{I}<1+\frac{\left(1-\theta^{*}\right)\left(\eta+\xi^{J}\right)}{\left(1-\theta^{*}-\theta\right)}$, and
(iv) a decrease in $\delta$ if $\xi^{I} \geq \theta^{*}-\eta^{*}\left(1-\theta^{*}\right)$.

Comment. A reduction in $\beta$ reflects improved offshoring technology that spurs offshoring of tasks and hence an expansion of the range $[0, I]$. If an increase in the demand for offshoring raises the informal wage, then there is a greater incentive to complete some tasks in the developing nation's formal sector and the range of outsourcing $[0, J]$ decreases. Finally, if technological improvements do not spur a lot of offshoring, then cost savings that raise scale must raise the demand for labor in the developed nation's manufacturing sector, pushing up $w^{*}$. This is similar to the productivity effect on the developed nation's wage noted in both GRH and Bandyopadhyay et al. (2020). The effect of $\beta$ on the equilibrium share $\delta$ is more complicated and is discussed below.

The specific results in Proposition 1 are better understood by digging deeper. The decrease in $\beta$ has the following effects. First, it raises the relative factor price $\rho_{I}\left(=\frac{w^{*}}{\bar{w} \beta}\right)$ of completing a task in the developed nation, leading to more tasks being offshored

to the formal sector of the developing nation. Second, notice that $\beta$ is an offshoring cost parameter that reflects the labor required to move a task out of the developed nation and applies to both the formal and informal sectors. Therefore, a fall in $\beta$ at a given $I$ tends to reduce labor demand in both of these sectors. Finally, lower labor costs tend to drive down unit costs and a competitive equilibrium is restored through the expansion of scale. This last effect tends to raise the developing nation's labor demand. The sum of these three effects determines whether the developing nation's labor demand as a whole rises or falls in response to a fall in $\beta$. When $\xi^{I}>\theta^{*}-\eta^{*}\left(1-\theta^{*}\right)$, the demand for offshore labor responds strongly to a change in the effective factor price $\rho_{I}$. In this case, the expansionary effect on labor demand dominates and the developing nation's labor market clears when more labor flows into the nation's manufacturing sector from its agricultural sector $(y)$ through a rise in the wage $w$ (recall that the labor supply of the manufacturing sector $L(w)$ is positively sloped). When $w$ rises, the effective relative factor price for the formal sector $\rho_{J}=\bar{w} /(\tilde{\beta} w)$ must fall. This reduces formal-informal outsourcing J. Turning to the effect on the developed nation's wage, notice that if $\xi^{I}$ is relatively small, the effect of a shift in labor demand is relatively small (toward the developing nation) and dominated by the scale expansion effect and hence $w^{*}$ rises. Finally, the relative size of the informal sector $\delta$ must fall when $\xi^{I} \geq \theta^{*}-\eta^{*}\left(1-\theta^{*}\right)$ because the relative size is independent of scale, and hence all that matters is the range of tasks that are outsourced from the formal to the informal sector. Since $J$ falls when $\xi^{I}>\theta^{*}-\eta^{*}\left(1-\theta^{*}\right)$, a smaller range of tasks are completed in the informal sector. Even when $\xi^{I}=\theta^{*}-\eta^{*}\left(1-\theta^{*}\right)$, the relative size of the informal sector must fall because $J$ remains unchanged but $I$ rises, which means that a higher fraction of offshored tasks are now completed in the formal sector.

\subsection{Technological Improvements in the Informal Sector (Fall In $\tilde{\beta})$ :}

The effect of a rise in informal sector productivity (i.e., fall in $\tilde{\beta}$ ) can be obtained by using equations (12) and (14): 


$$
\begin{gathered}
\frac{\hat{w}}{\hat{\tilde{\beta}}}=\frac{-\theta^{*}\left(\xi^{J}-\delta\right)-\left(1-\theta^{*}-\theta\right)\left(\eta^{*}+\xi^{I}\right)}{\theta^{*}\left(\eta+\xi^{J}\right)+\left(1-\theta^{*}-\theta\right)\left(\eta^{*}+\xi^{I}\right)} \text { and } \\
\frac{\hat{w}^{*}}{\hat{\tilde{\beta}}}=\frac{-\left(1-\theta^{*}-\theta\right)(\delta+\eta)}{\theta^{*}\left(\eta+\xi^{J}\right)+\left(1-\theta^{*}-\theta\right)\left(\eta^{*}+\xi^{I}\right)}
\end{gathered}
$$

Proposition 2. A reduction in $\tilde{\beta}$ leads to

(i) an increase in the range of offshoring $[0, I]$ and also an increase in the range offormal-

informal outsourcing $[0, J]$,
(ii) an increase in $w$ if and only if $\xi^{J}>\delta-\frac{\left(1-\theta^{*}-\theta\right)\left(\eta^{*}+\xi^{I}\right)}{\theta^{*}}$,

(iii) an increase in $w^{*}$, and

(iv) a decrease in $\delta$ if the $\tau(i)$ schedule is relatively steep at $i=J$.

Comment. A reduction in $\tilde{\beta}$ reflects an improved technology of outsourcing from the formal to the informal sector. The first-round effect should be an increase in the range $[0, J]$ of tasks performed in the informal sector. However, the cost reduction for firms spurs scale expansion and raises demand for labor in the developed nation, raising $w^{*}$ and spurring more offshoring. Thus, the range of offshoring $[0, I]$ rises. If $\tau(i)$ is steep, then there is not much scope for increasing outsourcing, hence share $\delta$ falls. The effect on $w$ is more nuanced and explained in more detail in the discussion that follows.

At the initial $w$, the fall in $\tilde{\beta}$ raises the effective factor price $\rho_{J}=\bar{w} /(\tilde{\beta} w)$ of completing the tasks in the formal sector compared with the informal sector, which shifts more tasks to the informal sector (i.e., J rises). However, because of the decline in $\tilde{\beta}$, each informal sector task requires less labor, which creates a cost reduction at the initial equilibrium that leads to reallocations that increase scale. The scale expansion drives up labor demand in the developed nation, raising $w^{*}$ and hence $\rho_{I}=w^{*} /(\beta \bar{w})$. Thus, more tasks are offshored. There are different opposing effects on demand in the informal sector. First, labor demand in the informal sector decreases due to greater efficiency from a lower $\tilde{\beta}$. On the other hand, increased offshoring, increased outsourcing of tasks to the informal sector, and scale expansion all suggest an increase in the labor demand of the manufacturing sector of the developing nation. When the offshoring and outsourcing elasticities $\left(\xi^{I}, \xi^{J}\right)$ are relatively large, the inequality in part (ii) of Proposition 2 is more likely to be satisfied, and the expansionary effects dominate the contractionary effect of labor-saving technological improvements. In this case, aggregate labor demand of the manufacturing sector of the developing nation rises. The labor market clears at a higher wage $w$, where more labor moves from the agricultural sector to the manufacturing sector in the developing nation. Finally, consider the ratio of formal-to-informal sector labor employment. Suppose $\tau(i)$ is very steep at the initial equilibrium. As $\tilde{\beta}$ falls, there is not much of a change in $J$ because $\tau$ rises rapidly to equal the new factor price $\rho_{J}$. Without much change in $J$, there are two effects of a fall in $\tilde{\beta}$, both of which reduce the ratio $\delta$. First, each informal sector task requires less labor, which shrinks this sector's relative employment through the laborsaving effect. Second, as $I$ rises in response to a higher $w^{*}$, a rigid $J$ means a greater range of tasks $[J, I]$ are completed in the formal sector. This effect also shrinks $\delta$. In other words, unless 


\section{Bandyopadhyay, Basu, Chau, Mitra}

the $\tau(i)$ schedule is sufficiently flat to allow for an elastic response of $J$ to a rise in $\rho_{J}$, the share of informal sector employment is inversely related to informal sector productivity.

\subsection{The Effects of a Change in the Minimum Wage}

If the developing nation's government decides to change the minimum wage, the effects can be analyzed using equations (12) and (14) as follows:

$$
\begin{aligned}
& \frac{\hat{w}}{\hat{\bar{w}}}=\frac{-\theta^{*}\left(\xi^{I}-\xi^{J}\right)-\theta\left(\eta^{*}+\xi^{I}\right)}{\theta^{*}\left(\eta+\xi^{J}\right)+\left(1-\theta^{*}-\theta\right)\left(\eta^{*}+\xi^{I}\right)}, \\
& \frac{\hat{w}^{*}}{\hat{\bar{w}}}=\frac{\left(1-\theta^{*}\right)\left(\xi^{I}-\xi^{J}\right)-\theta\left(\eta+\xi^{I}\right)}{\theta^{*}\left(\eta+\xi^{J}\right)+\left(1-\theta^{*}-\theta\right)\left(\eta^{*}+\xi^{I}\right)} .
\end{aligned}
$$

Proposition 3. A reduction in $\bar{w}$ leads to

(i) an increase in the range of offshoring $[0, I]$ and a decrease in the range offormal-

informal outsourcing $[0, J]$,
(ii) an increase in $w$ if and only if $\xi^{I}>\frac{\theta^{*} \xi^{J}-\theta \eta^{*}}{\theta^{*}+\theta}$,

(iii) an increase in $w^{*}$ if and only if $\xi^{I}<\frac{\left(1-\theta^{*}\right) \xi^{J}+\eta \theta}{1-\theta^{*}-\theta}$, and
(iv) a decrease in $\delta$.

Comment. A minimum-wage cut reduces the effective wage of completing the marginal offshored task in the formal sector of the developing nation, which must raise the range of offshoring $[0, I]$. In addition, it also reduces the effective cost of completing the marginal outsourced task in the formal sector compared with the informal sector. Thus, fewer tasks are done in the informal sector, reducing the outsourcing range $[0, J]$ and also the relative size of the informal sector $\delta$. The wage effects are more nuanced and are better understood in the detailed discussion below.

A cut in $\bar{w}$ raises the relative price of completing tasks in the developed nation (i.e., $\rho_{I}$ ) and reduces the relative price $\rho_{J}$ of completing tasks in the developing nation's formal sector (vis-á-vis the informal sector). This expands the offshoring margin $I$ and shrinks outsourcing margin $J$ and has three effects on the informal wage $w$. First, as the marginal offshored task $I$ rises, demand shifts from the developed to the developing nation, tightening the latter's labor market and exerting upward pressure on $w$. Second, at a lower minimum wage, more tasks are completed in the developing nation's formal sector, reducing the demand for labor in the informal sector, which has a negative impact on the informal wage. Finally, lowering the unit cost at the initial equilibrium leads to scale expansion, which raises demand in all of the labor markets, exerting upward pressure on all the flexible factor prices. If $\xi^{I}$ is large relative to $\xi^{J}$, the formal-informal reallocation effect (i.e., the second effect) is small and the expansionary effects dominate. The net increase in the manufacturing sector's demand for labor in the developing nation drives up the informal wage $w$. Finally, the comparative statics effect on $w^{*}$ is best understood by focusing on how the factor rewards $\left(w^{*}, \bar{w}, w\right)$ in the unit cost function may 
change vis-á-vis each other. When $\bar{w}$ falls, given the technology and output price, zero profit requires that at least one of the factor rewards $\left(w^{*}, w\right)$ rises. When $\xi^{J}$ is large relative to $\xi^{I}$, demand shifts disproportionately from the informal to the formal sector in response to the minimum-wage cut. In this situation, there may be a net reduction in the developing nation's manufacturing sector's labor demand, which requires $w$ to fall to clear the market. When $w$ falls, the only possible outcome consistent with a zero-profit equilibrium is a higher $w^{*}$. Put differently, if $\xi^{J}$ is relatively small, then it is possible that the informal wage $w$ rises (as explained above)-to such an extent that even at a lower $\bar{w}$ zero profit can be reestablished only through a fall in $w^{*}$. It is easy to check that $\frac{\theta^{*} \xi^{J}-\theta \eta^{*}}{\theta^{*}+\theta}<\frac{\left(1-\theta^{*}\right) \xi^{J}+\eta \theta}{1-\theta^{*}-\theta}$. Using this fact and part (iii) of Proposition 3, we have that if $w^{*}$ falls, it must be that $\xi^{I}>\frac{\left(1-\theta^{*}\right) \xi^{J}+\eta \theta}{1-\theta^{*}-\theta} \Rightarrow \xi^{I}>\frac{\theta^{*} \xi^{J}-\theta \eta^{*}}{\theta^{*}+\theta}$. In turn, using part (ii) of the proposition and the last inequality in the previous sentence, it must be that a necessary (but not sufficient) condition for $w^{*}$ to fall is a rise in $w$. In other words, a rising factor reward in the informal sector is what allows the developed nation's wage to fall in spite of the fall in the developing nation's minimum wage. Finally, notice that a larger $I$ and a smaller $J$ in response to a minimum-wage cut imply that fewer tasks $[0, J]$ are completed in the informal sector and a greater range of tasks $[J, I]$ are completed in the formal sector. Thus, the ratio of informal sector employment $\delta$ must decline.

\section{CONCLUSION}

This article argues that given the overwhelming importance of the informal sector in many developing nations, it is important to consider the dual labor-market structure that characterizes these nations. It is important not only because the structure is closer to reality, but also because it leads to important differences in the comparative statics responses. While GRH and Bandyopadhyay et al. (2020) both point to developed-nation wage increases due to the productivity effect, we find that the dual labor-market feature can overturn this effect. We see this in Proposition 1 of this article, which notes the possibility of a reduction in the developed nation's wage, in contrast to Proposition 1 of Bandyopadhyay et al. (2020). The reduction is possible because when offshoring elasticity is large, the increase in labor demand in the developing nation can push up costs on two fronts: a higher informal wage and a greater share of the work performed in the relatively higher-cost formal sector. These reallocation effects and factor price changes allow a fall in the developed nation's wage in spite of technological improvements.

Other important factors that are missed by models that do not consider the informal sector is the possibility of purely domestic factors that can raise the productivity of the informal sector. While the direct effect of such changes is a boost in the informal sector, the indirect effect encompasses the offshoring decision as well as the developed nation's wage. With more work being done more efficiently by the informal sector and with the factor price of the formal sector being held constant by the minimum wage, the developed nation's wage s must rise to reflect this efficiency. Such an international effect of a purely domestic technological change 


\section{Bandyopadhyay, Basu, Chau, Mitra}

is missed by models that ignore the dual labor-market structure. Finally, without a dual labormarket structure, one cannot fruitfully talk about the impact of changes in minimum-wage laws on the vast majority of urban informal workers. Our work shows that while a cut in the minimum wage will shrink the relative size of the informal sector, informal workers can actually be better off because of a rise in the informal wage through the expansionary effects of a minimum-wage cut.

Our agenda for future work on the topic of dual labor markets includes the analysis of the effects of different types of labor standards (including the minimum wage) after allowing for imperfect monitoring of these standards in the formal sector. It is also relevant to look at competing offshoring destinations and how labor standards or the degree of informality in one nation affects other offshoring recipients and possibly their labor standards. Finally, we have abstracted in this article from considerations arising out of terms-of-trade changes in the output market. Interactions between output-market terms of trade and factor-market terms of trade in the presence of informality is another possible avenue for our future work.

\section{APPENDIX}

\section{A1. PROOF OF PROPOSITION 1}

Given $\bar{w}$, the definition of $\rho_{I}$ in (7), and also (15), we get

$$
\frac{\hat{\rho}_{I}}{\hat{\beta}}=\frac{\hat{w}^{*}}{\hat{\beta}}-1=\frac{-\left(1-\theta^{*}-\theta\right)\left(1+\eta^{*}\right)-\left(\eta+\xi^{J}\right)}{\theta^{*}\left(\eta+\xi^{J}\right)+\left(1-\theta^{*}-\theta\right)\left(\eta^{*}+\xi^{I}\right)}<0 .
$$

Equation (A1) implies that a fall in $\beta$ must raise $\rho_{I}$. Therefore, using (7), we have that $I$ must rise when $\beta$ falls $\left(\frac{d I}{d \beta}<0\right)$. The first relationship in (15) establishes that $\frac{\hat{w}}{\hat{\beta}}<0 \Leftrightarrow \xi^{I}>\theta^{*}-\eta^{*}\left(1-\theta^{*}\right)$. Notice from the definition of $\rho_{J}$ that given $(\tilde{\beta}, \bar{w}), \hat{\rho}_{J}=-\hat{w}$. Thus, $\frac{\hat{\rho}_{I}}{\hat{\beta}}=-\frac{\hat{w}}{\hat{\beta}}>0 \Leftrightarrow \xi^{I}>\theta^{*}-\eta^{*}\left(1-\theta^{*}\right)$. In turn, from (8) we get $\frac{\hat{J}}{\hat{\beta}}>0 \Leftrightarrow \xi^{I}>\theta^{*}-\eta^{*}\left(1-\theta^{*}\right)$. Now, the second relationship in (15) shows that $\frac{\hat{w}^{*}}{\hat{\beta}}<0 \Leftrightarrow \xi^{I}<1+\frac{\left(1-\theta^{*}\right)\left(\eta+\xi^{J}\right)}{\left(1-\theta^{*}-\theta\right)}$. Finally, notice that $\delta=\frac{\tilde{\beta} \mu}{\tilde{\beta} \mu+\gamma}=\frac{\tilde{\beta}}{\tilde{\beta}+\lambda(J, I)}$, where $\lambda(J, I) \equiv \frac{\gamma}{\mu}=\frac{\int_{J}^{I} t(i) d i}{\int_{0}^{I} t(i) \tau(i) d i}$. As shown above, when $\xi^{I} \geq \theta^{*}-\eta^{*}\left(1-\theta^{*}\right), w$ will either rise or be constant when $\beta$ falls. Thus, the marginal task $J$ will either fall or remain constant. The increase in $I$ without any increase in $J$ means that the numerator of the expression for $\lambda(J, I)$ rises, but the denominator remains constant or falls. Thus, $\lambda(J, I)$ must rise, implying that $\delta$ must fall when $\xi^{I} \geq \theta^{*}-\eta^{*}\left(1-\theta^{*}\right)$. 


\section{A2. PROOF OF PROPOSITION 2}

The second relationship in (16) shows that the developed nation's wage $w^{*}$ must always rise when $\tilde{\beta}$ falls. In turn, this means that $\rho_{I}=w^{*} /(\beta \bar{w})$ must rise, which implies that $I$ must rise.

Using the first relationship in (16) we get

$\frac{\hat{w}}{\hat{\tilde{\beta}}}+1=\frac{\theta^{*}(\eta+\delta)}{\theta^{*}\left(\eta+\xi^{J}\right)+\left(1-\theta^{*}-\theta\right)\left(\eta^{*}+\xi^{I}\right)}>0 \Leftrightarrow \frac{d(w \tilde{\beta})}{d \tilde{\beta}}>0$. Thus, $\rho_{J}=\bar{w} /(\tilde{\beta} w)$ must rise when

$\tilde{\beta}$ falls, which implies that $J$ must rise. Using the first relationship in (16) we find that

$\xi^{J}>\delta-\frac{\left(1-\theta^{*}-\theta\right)\left(\eta^{*}+\xi^{I}\right)}{\theta^{*}}$ is a necessary and sufficient condition for the informal wage $w$ to rise when $\tilde{\beta}$ falls. Turning to the relative size of the informal sector, recall that

$\delta=\frac{\tilde{\beta}}{\tilde{\beta}+\lambda(J, I)}$, where $\frac{\gamma}{\mu}=\frac{\int_{J}^{I} t(i) d i}{\int_{0}^{J} t(i) \tau(i) d i} \equiv \lambda(J, I)$. A fall in $\tilde{\beta}$ for a given $\lambda$ reduces $\delta$. However, since $I$ and $J$ both rise, the direction of the change in $\lambda$ is, in general, ambiguous. If the $\tau(i)$ schedule is steep at $i=J$, the comparative static change in $J$ will be small. In this event, the denominator for the expression for $\lambda$ does not change much, but the numerator rises because of a rise in $I$. Thus, $\lambda$ rises (assuming that $t(i)$ is not too steep at $i=I$ ). Therefore, in this case, a reduction in $\tilde{\beta}$ and an increase in $\lambda$ both reduce $\delta$. If both schedules $t(i)$ and $\tau(i)$ are steep, the offshoring and outsourcing margins do not change much and $\lambda$ does not change much. However, the fall in $\tilde{\beta}$ reduces $\delta$. Therefore, as long as $\tau(i)$ is sufficiently steep at $i=J$, the informal share $\delta$ must fall with a fall in $\tilde{\beta}$.

\section{A3. PROOF OF PROPOSITION 3}

Using equations (7), (8), and (17) for a given $\beta$ and $\tilde{\beta}$, we get $\frac{\hat{\rho}_{I}}{\hat{\hat{w}}}=\frac{\hat{w}^{*}}{\hat{\bar{w}}}-1<0$ and $\frac{\hat{\rho}_{J}}{\hat{\hat{w}}}=1-\frac{\hat{w}}{\hat{\hat{w}}}>0$. These imply that a minimum-wage cut must raise $\rho_{I}$ and reduce $\rho_{J}$. In turn, equations (7) and (8) show that $I$ must rise and $J$ must fall. The two inequalities in (17) yield $\frac{\hat{w}}{\hat{\bar{w}}}>0$ if and only if $\xi^{I}<\frac{\theta^{*} \xi^{J}-\theta \eta^{*}}{\theta^{*}+\theta}$ and $\frac{\hat{w}^{*}}{\hat{\bar{w}}}<0$ if and only if $\xi^{I}<\frac{\left(1-\theta^{*}\right) \xi^{J}+\eta \theta}{1-\theta^{*}-\theta}$. Finally, recall that $\delta=\frac{\tilde{\beta}}{\tilde{\beta}+\lambda(J, I)}$, where $\lambda(J, I)=\frac{\int_{J}^{I} t(i) d i}{\int_{0}^{J} t(i) \tau(i) d i}$. As I rises and $J$ falls, the numerator of the expression for $\lambda$ rises and the denominator shrinks. Thus, $\lambda$ rises as the minimum wage falls, meaning that $\delta$ must fall. 


\section{Bandyopadhyay, Basu, Chau, Mitra}

\section{NOTES}

1 Bandyopadhyay et al. (2020) also present their main results in the context of two nations that are small in the output market. The appendix of their paper considers how the analysis may be extended to large countries and how that can modify their findings.

$\underline{2}$ The more-complex tasks will also be more costly to domestically outsource, since greater skills might be required to perform them and skills cannot be fully transferred from the formal to the informal sector. Also, supervision by formal-firm managers of informal sector firms or of casual workers is more difficult. Informal workers, due to the temporary nature of their jobs, have little incentive to acquire skills on the job. For the same reason, their employers have virtually no incentive to invest in their human capital or productivity. Despite the low productivity of informal workers, formal firms transfer some of the relatively simple tasks to them because of the lower informal sector wage.

3 See, for example, Goldschmidt and Schmieder (2017), where "domestic outsourcing" in Germany is analyzed.

4 The small-nation assumption in the output market considerably simplifies the analysis of factor markets by ensuring that any excess supply or excess demand in the output market is absorbed by the world market at fixed international prices. Utility of each nation is entirely determined by national income because output prices are fixed in the indirect utility function of each nation. Of course, national income is endogenous and determined by factor allocation between the two sectors-manufacturing and agriculture. Excess labor supply from agriculture in each nation is absorbed under labor market clearing (modeled) in the offshoring manufacturing sector. Technological change affects allocation of labor both between the sectors and across the nations, and all of this is considered in our analysis. Dropping the small-nation assumption is possible, and following Bandyopadhyay et al. (2020, pp. 222-23) we may pursue this line of inquiry in our future work. The analysis is done in the context of a representative North-South model of offshoring. It may be possible to extend the analysis to several such nations to characterize the global economy. However, such a model is much more complex and beyond the scope of this article.

$\underline{5}$ We assume that the technology in sectors $\left(y, y^{*}\right)$ and the endowments $\left(\bar{L}, \bar{L}^{*}\right)$ are such that there is an excess supply of labor in the agricultural sector for the relevant range of wages within which a sensible interior offshoring equilibrium (described in the next section) obtains.

$\underline{6}$ In our competitive model, each firm hires similarly and the excess labor supply is absorbed at a flexible wage that prevails in the informal sector and in the agricultural sector. In a model of heterogeneous firms (that will require some sort of imperfect competition, such as monopolistic competition with product differentiation) with firmspecific wage negotiations, although the minimum wage may not be binding for all firms, it could be binding for the marginal firm. Our competitive model captures this behavior in a simple and tractable way without invoking a monopolistically competitive framework and the associated complexity.

$\underline{7}$ Note that equations (7) and (8) above show that $I$ is entirely determined by $\rho_{I}=w^{*} /(\beta \bar{w})$ and $J$ by $\rho_{J}=\bar{w} /(\tilde{\beta} w)$. If we explicitly note these relationships in equation (11), then we get a relationship between the factor prices $\left(w, w^{*}, \bar{w}\right)$ and the technology parameters $(\beta, \tilde{\beta})$. For analytical convenience, we take a slightly different approach, although this aforementioned relationship is at the heart of equation (13) later in the text. Equation (13) captures the labormarket equilibrium in the two nations in the presence of offshoring, outsourcing, and formal-informal duality. On the other hand, equation (14) is derived from the zero-profit condition of competitive firms and also represents a relationship between these factor prices and technology parameters. Equation (14) ensures that a representative firm's scale has to adjust to ensure price-unit cost equality. Equations (13) and (14) together characterize the comparative static effects of parametric changes.

8 Notice that $\frac{\partial(\tilde{\beta} \mu+\gamma)}{\partial J}=\frac{t(J)[\tilde{\beta} \tau(J)-1]}{1-I}>0$, because using equation (8), we have $\tilde{\beta} \tau(J)=\frac{\bar{w}}{w}>1$.

9 Proofs of all propositions are provided in an appendix. 
Bandyopadhyay, Basu, Chau, Mitra

\section{REFERENCES}

Bandyopadhyay, S.; Basu, A.K.; Chau, N.H. and Mitra, D. “Consequences of Offshoring to Developing Nations: Labor-Market Outcomes, Welfare, and Corrective Interventions." Economic Inquiry, 2020, 58(1), pp. 209-24; https://doi.org/10.1111/ecin.12833.

Bhagwati, J. and Panagariya, A. Why Growth Matters? How Economic Growth in India Reduced Poverty and the Lessons for Other Developing Countries. New York: Public Affairs, 2013.

Goldschmidt, D. and Schmieder, J.F. "The Rise of Domestic Outsourcing and the Evolution of the German Wage Structure." Quarterly Journal of Economics, 2017, 132(3), pp. 1165-217.

Grossman, G.M. and Rossi-Hansberg, E. "Trading Tasks: A Simple Theory of Offshoring." American Economic Review, 2008, 98(5), pp. 1978-97; https://doi.org/10.1257/aer.98.5.1978.

Harris-White, B. and Sinha, A. Trade Liberalization and India's Informal Economy. Oxford University Press, 2007.

Hasan, R. and Jandoc, K.R.L. "Labor Regulations and Firm-Size Distribution in Indian Manufacturing," in J. Bhagwati and A. Panagariya, eds., Reforms and Economic Transformation in India. Oxford University Press, 2013, pp. 15-48.

Ramaswamy, K.V. "Liberalization, Outsourcing and Industrial Labor Markets in India: Some Preliminary Results," in S. Uchikawa, ed., Labor Market and Institution in India: 1990s and Beyond. Manohar, 2003.

Samaniega de la Parra, B. "Formal Firms, Informal Workers and Household Labor Supply in Mexico." Unpublished manuscript, Department of Economics, University of Chicago, 2016.

Sundaram, A. "The Impact of Trade Liberalization on Micro Enterprises: Do Banks Matter? Evidence from Indian Manufacturing." Oxford Bulletin of Economics and Statistics, 2015, 77(6), pp. 832-853; https://doi.org/10.1111/obes.12082.

Sundaram, A.; Ahsan, R.N. and Mitra, D. "Complementarity between Formal and Informal Manufacturing in India: The Role of Policies and Institutions," in J. Bhagwati and A. Panagariya eds., Reforms and Economic Transformation in India. Oxford University Press, 2012, pp. 49-85. 
